\title{
Studying the variability in the diurnal and seasonal variations in GPS total electron content over Nigeria
}

\author{
Victor Adetayo Eyelade ${ }^{1}$, Adekola Olajide Adewale ${ }^{2}$, Andrew Ovie Akala ${ }^{2}$, Olawale Segun Bolaji ${ }^{2}$, and \\ A. Babatunde Rabiu ${ }^{1}$ \\ ${ }^{1}$ Centre for Atmospheric Research, National Space Research and Development Agency, Anyigba, Nigeria \\ ${ }^{2}$ Department of Physics, Faculty of Science, University of Lagos, Akoka, Lagos State, Nigeria \\ Correspondence to: A. Babatunde Rabiu (tunderabiu2@gmail.com)
}

Received: 4 July 2016 - Revised: 2 May 2017 - Accepted: 3 May 2017 - Published: 6 June 2017

\begin{abstract}
The study of diurnal and seasonal variations in total electron content (TEC) over Nigeria has been prompted by the recent increase in the number of GPS continuously operating reference stations (CORSs) across Nigeria as well as the reduced costs of microcomputing. The GPS data engaged in this study were recorded in the year 2012 at nine stations in Nigeria located between geomagnetic latitudes 4.33 and $0.72^{\circ} \mathrm{N}$. The GPS data were used to derive GPS TEC, which was analysed for diurnal and seasonal variations. The results obtained were used to produce local GPS TEC maps and bar charts. The derived GPS TEC across all the stations demonstrates consistent minimum diurnal variations during the pre-sunrise hours 04:00 to 06:00 LT, increases with sharp gradient during the sunrise period $(\sim 07: 00$ to 09:00 LT), attains postnoon maximum at about 14:00 LT, and then falls to a minimum just before sunset. Generally, daytime variations are found to be greater than nighttime variations, which range between 0 and 5 TECU. The seasonal variation depicts a semi-annual distribution with higher values $(\sim 25-30 \mathrm{TECU})$ around equinoxes and lower values ( 20-25 TECU) around solstices. The December Solstice magnitude is slightly higher than the June Solstice magnitude at all stations, while March Equinox magnitude is also slightly higher than September Equinox magnitude at all stations. Thus, the seasonal variation shows an asymmetry in equinoxes and solstices, with the month of October displaying the highest values of GPS TEC across the latitudes.
\end{abstract}

Keywords. Ionosphere (equatorial ionosphere)

\section{Introduction}

The global age-long interest in the ionosphere is apparently being sustained due to its tremendous applications in radio communications (Rama Rao et al., 1997; Rabiu et al., 2013). The variation in ionosphere with time and location on earth necessitates its study at several points on earth for a long time. The equatorial and low-latitude ionosphere manifests a number of unique phenomena, such as the equatorial electrojet (EEJ), equatorial spread $\mathrm{F}$ (ESF), equatorial plasma bubble (EPB), and equatorial ionization anomaly (EIA) among others, and is characterized by large transient variations (Bagiya et al., 2009; Mukherjee et al., 2010; Chauhan et al., 2011; Bolaji et al., 2012). The equatorial ionosphere is highly dynamic and consequently poses serious threats to communication and navigation systems (Akala et al., 2010, 2011, 2012).

The ionospheric parameter that has an overbearing influence on GPS-based communication and navigation systems is the total electron content (TEC) (Akala et al., 2013). TEC is the number of electrons in the column of $1 \mathrm{~m}^{2}$ cross section that extends from a GPS satellite to a GPS receiver. This important parameter is a by-product of GPS data, which can also be used to survey the ionosphere and can be used to provide an overall description of the ionosphere (Mukherjee et al., 2010).

Bilitza (2001) rightly noted that a good description of the variability in ionospheric magnitudes is a necessary prerequisite for improvement of the performance of the ionospheric models. Studies on diurnal variation in TEC reveal useful information about the physical processes responsible for the ionospheric behaviour and TEC is fast becoming an impor- 
tant parameter for both geophysical and engineering applications (Pandey et al., 2001; Mukherjee et al., 2010). In Nigeria, Bolaji et al. (2012) reported that during low solar activity the TEC over Ilorin, a station close to the trough of the EIA, exhibits consistent minimum diurnal variation during presunrise hours between 05:00 and 06:00 LT, rises steeply during the sunrise period (07:00-09:00 LT), and subsequently rises very slowly from 10:00 LT to the peak during the daytime, mostly around 12:00-16:00 LT. Bagiya et al. (2009) had earlier reported similar diurnal variation patterns during low solar activity periods near the crest region of the EIA in India and confirmed that the diurnal characteristics of TEC depend on season, solar activity, geomagnetic activity, and latitude.

The F2 layer in the vicinity of the magnetic dip equator is characterized by a depression, or trough, in the ionization density at the equator and two humps, one on each side of the equator (at about $\pm 17^{\circ}$ magnetic latitude) during the day that lasts for several hours after sunset. This interesting phenomenon is called the equatorial ionospheric anomaly (EIA) or the Appleton anomaly (Appleton, 1946). The cause of the anomaly is often attributed to the so-called fountain effect, whereby an eastward electric field at the equator gives rise to an upward $\boldsymbol{E} \times \boldsymbol{B}$ drift during the daytime. After the plasma is lifted to greater heights it is able to diffuse downward along magnetic field lines under the influence of gravity and pressure gradient forces. The net result is the formation of a plasma fountain, which produces an enhanced plasma concentration (crest) at higher latitudes and a reduced plasma concentration (trough) at the equator. The daytime dynamo-generated eastward electric field combined with the northward geomagnetic field lifts the equatorial ionosphere from $700 \mathrm{~km}$ up to over $1000 \mathrm{~km}$. After losing momentum, the electrons diffuse along the field lines to either side of the equator to form two crests (Yeh et al., 2001).

Rama Rao et al. (2006a) studied the temporal and spatial variations in GPS TEC using simultaneous measurements from the Indian GPS network of receivers during the low solar activity period and observed that the diurnal variation in the EIA region reaches its maximum value between 13:00 and 16:00 LT, whereas near the equator the daytime maximum is broad and its peak is delayed and occurs around 16:00 LT. Similarly, the daytime minimum in GPS TEC occurs between 05:00 and 06:00 LT at all stations from the equator to the EIA crest region. However, beyond the crest region an extended day minimum is found to occur, which is flat during most of the nighttime hours, a feature that is similar to that at mid-latitudes. The diurnal variation in GPS TEC shows a minimum to maximum variation in about 5$50 \mathrm{TECU}$ at the equator and from 5 to $90 \mathrm{TECU}$ at the EIA crest region.

The seasonal variations in vertical TEC are higher during the equinox than the solstice during low solar activity (Wu et al., 2004; Bagiya et al., 2009; Chauhan et al., 2011) and high solar activity (Natali and Meza, 2011) at different stations.
Rama Rao et al. (2006a) observed that the seasonal variation in TEC reaches a maximum during the equinoctial months followed by winter and is at a minimum in the summer, a feature similar to that observed by Rabiu et al. (2013) in the Indian EEJ strength for the corresponding seasons. Scherliess and Fejer (1999) had earlier inferred that daytime $\boldsymbol{E} \times \boldsymbol{B}$ drift velocities are larger in the equinoctial months and winter months than in the summer months, and this could result in semi-annual variation. Olatunji (1967), Bailey et al. (2000), and Liu et al. $(2006,2009)$ found that this semi-annual variation is related to the variation in the noon solar zenith angle, which is an important factor in ionization. Wu et al. (2004), Rama Rao et al. (2006a, b), and Lee et al. (2010) attributed the semi-annual variation to a combined effect of solar zenith angle and geomagnetic field geometry.

Quantitative study of transient variations in GPS TEC, involving simultaneously measured data from multiple stations in Nigeria, has been hindered over the years due to the dearth of distributed GPS facilities. Recent deployment of a network of Nigerian GNSS Reference Network (NIGNET) CORS by the Nigerian Office of the Surveyor General, as well as the reduced costs of microcomputing, provided an essential foundation for this study. The present study attempts to investigate the diurnal and seasonal variations in GPS TEC obtained from simultaneous GPS measurements from nine locations in Nigeria, a region under the equatorial anomaly region, covering geomagnetic coordinates bounded between geomagnetic longitudes 75.45 and $84.31^{\circ} \mathrm{E}$ and geomagnetic latitudes -4.33 and $0.72^{\circ} \mathrm{N}$.

\section{Data and method of analysis}

The study locations consisted of nine stations distributed over Nigeria, a region within the equatorial and low latitudes. The selected locations and their details, including their geographical and geomagnetic coordinates, are shown in Table 1 in order of increasing latitude.

A Nigerian map showing the locations of the various selected stations is shown in Fig. 1. Raw GPS (observable) data in RINEX format for these nine stations were used for this research work. The Ionospheric GPS TEC was obtained from the ground-based GPS receiver stations of NIGNET equipment being operated by the Office of the Surveyor General of the Federation (OSGoF) of Nigeria for the year 2012. Description of the NIGNET network and the managing agency is given in Rabiu et al. (2014) and Ayorinde et al. (2016).

The slant TEC (STEC) records obtained from GPS are polluted with satellite differential delay ( $b_{S}$, satellite bias) and receiver differential delay $\left(b_{\mathrm{R}}\right.$, receiver bias), coupled with receiver inter-channel bias $\left(b_{\mathrm{R} X}\right)$. This uncorrected STEC measured at every 1 min interval from the GPS receiver derived from all the visible satellites at all the stations is converted to vertical TEC (VTEC). VTEC can be expressed as 
Table 1. The list of stations used in the study with their respective geographical and geomagnetic coordinates.

\begin{tabular}{llrrrr}
\hline ID & Location & Geo. lat $\left({ }^{\circ} \mathrm{N}\right)$ & Geo. long $\left({ }^{\circ} \mathrm{E}\right)$ & Mag. lat $\left({ }^{\circ} \mathrm{N}\right)$ & Mag. long $\left({ }^{\circ} \mathrm{E}\right)$ \\
\hline RUST & Port Harcourt & 4.80 & 6.98 & -4.33 & 78.76 \\
CLBR & Cross River & 4.95 & 8.35 & -4.30 & 80.09 \\
FPNO & Imo & 5.43 & 7.03 & -3.90 & 78.85 \\
UNEC & Enugu & 6.42 & 7.50 & -3.25 & 79.36 \\
ULAG & Lagos & 6.52 & 3.40 & -3.03 & 75.45 \\
OSGF & FCT & 9.03 & 7.49 & -1.64 & 79.50 \\
FUTY & Yola & 9.35 & 12.50 & -1.32 & 84.31 \\
ABUZ & Kaduna & 11.15 & 7.65 & -0.13 & 79.75 \\
BKFP & Kebbi & 12.47 & 4.23 & 0.72 & 76.62 \\
\hline
\end{tabular}

Geo: geographical co-ordinate. Mag: geomagnetic co-ordinate. Lat: latitude. Long: longitude.

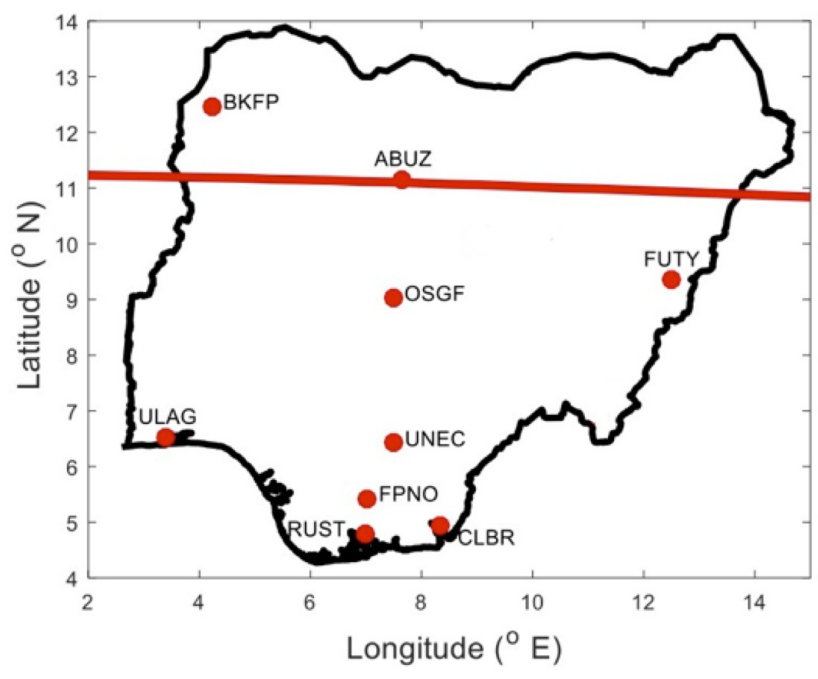

Figure 1. The distribution of the NIGNET GPS stations used for the study. The axes shows the geographical coordinates in degrees; the red solid line crossing near ABUZ is the magnetic equator.

$\mathrm{VTEC}=\mathrm{STEC}-\left[b_{\mathrm{R}}+b_{\mathrm{S}}+b_{\mathrm{R} X}\right] / S(E)$,

where STEC is the uncorrected slant TEC measured by the receiver, $S(E)$ is the obliquity factor with zenith angle $(z)$ at the ionospheric pierce point (IPP), $E$ is the elevation angle of the satellites in degrees, and VTEC is the vertical TEC at the IPP. The $S(E)$ is defined by Mannucci et al. (1993) and Langley et al. (2002) as follows:

$$
S(E)=\frac{1}{\cos (z)}=\left\{1-\left(\frac{R_{\mathrm{E}} \times \cos (E)}{R_{\mathrm{E}}+h_{\mathrm{S}}}\right)^{2}\right\}^{-0.5} .
$$

$R_{\mathrm{E}}$ is the mean radius of the earth measured in $\mathrm{km}$ and $h_{\mathrm{S}}$ is the height of the ionosphere from the surface of the earth, which is approximately equal to $350 \mathrm{~km}$. These analyses from Eqs. (1) and (2) were implemented in the GPS TEC analysis software developed and freely distributed by the Institute for Scientific Research, Boston College, MA, USA. The GPS TEC software runs on a Windows operating system with the availability of internet. The raw RINEX GPS data were processed using this GPS TEC analysis software. This software reads raw data, processes cycle slips in phase data, reads satellite biases from International GNSS Service (IGS) code file (if not available, it calculates them), calculates receiver bias, and calculates the inter-channel biases for different satellites in the receiver. To eliminate the effect due to multipath, a minimum elevation angle of $20^{\circ}$ is used. The VTEC data estimated are then subjected to a two-sigma $(2 \sigma)$ iteration, which is a measure of GPS point positioning accuracy $(95 \%$ confidence level). Research efforts that have utilized this GPS TEC software include the works of Bolaji et al. (2012, 2013), Olwendo et al. (2013), Rabiu et al. (2014), and Ayorinde et al. (2016), among others.

\section{Results and discussion}

\subsection{Diurnal variation in total electron content of the ionosphere over Nigeria}

The processed TEC data obtained from GPS TEC analysis software developed by the Institute of Scientific Research, Boston College, USA, gave GPS TEC data at minute intervals in ASCII format. These minute GPS TEC data were scaled down to hourly values for all the stations used. The time convention for these analyses is in local time (LT). Nigeria is $1 \mathrm{~h}$ ahead of Greenwich meridian time GMT; 01:00 UT is 02:00 LT in Nigeria. The hourly values of GPS TEC for each individual hour for all the days of the year from $1 \mathrm{Jan}$ uary to 31 December 2012 were collated together to obtain the diurnal variation. The hourly values of GPS TEC were plotted against local time to examine the hourly variation (diurnal) and this was done for the entire nine stations using surfer software package to generate the local TEC maps for each station as shown in Fig. 2. Surfer software has a built-in kriging function that enables it to account for miss- 

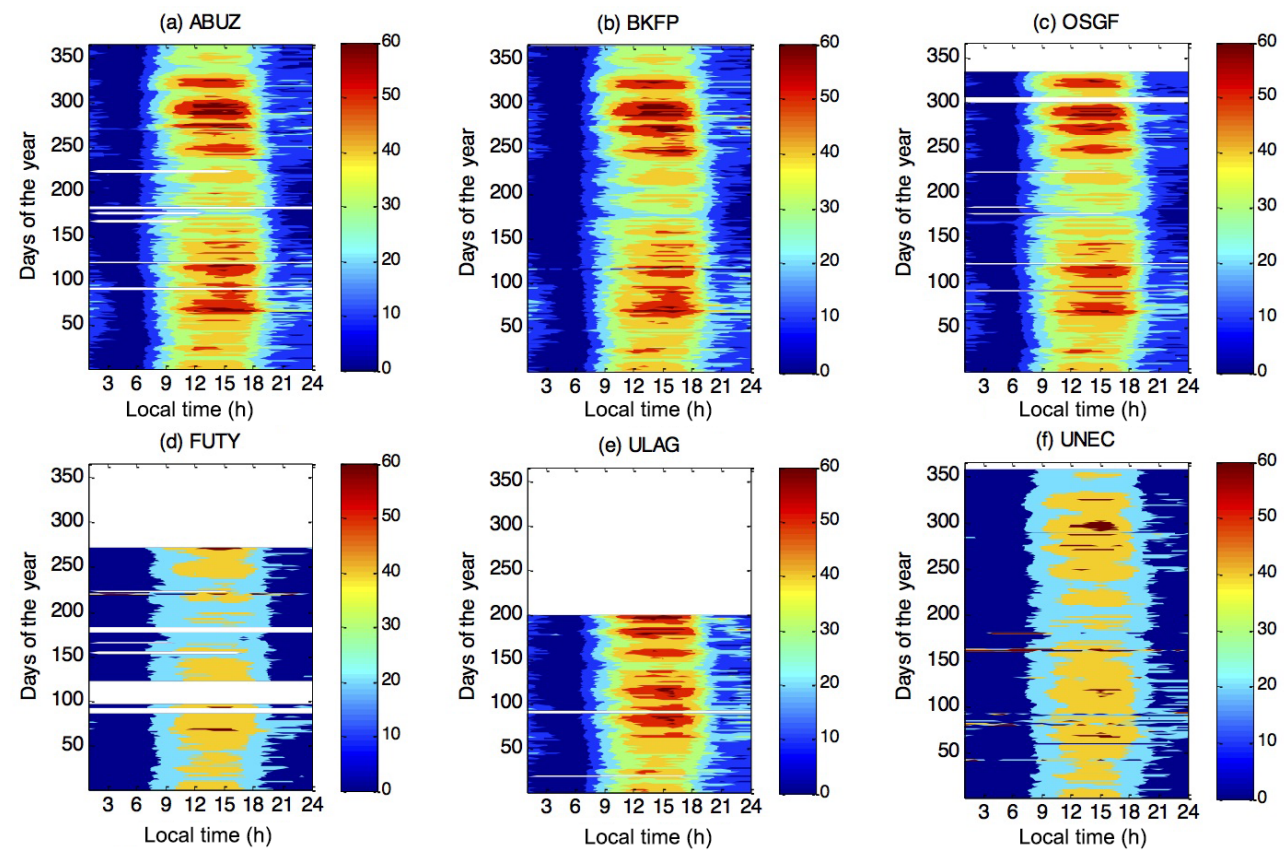

Figure 2. Contour plots of the diurnal variation in GPS TEC measured at the study areas in Nigeria. The white sections in the plots show unavailability of data.

ing data using appropriate interpolation techniques. However, only six stations out of the nine stations had consistent data that could translate to meaningful GPS TEC maps. The other three stations were afflicted with missing data due mainly to occasional power outages and so are not reported in Fig. 2. The diurnal variations in GPS TEC in all stations in Nigeria show characteristics typical of the low-latitude ionosphere (e.g. Rama Rao et al., 2006a, b and Rabiu et al., 2014). It is clearly shown from the plots that TEC exhibits consistent minimum diurnal variation during the pre-sunrise hours 04:00 to 05:00 LT with magnitude of 0 to 5 TECU, rises steeply during the sunrise period (07:00 to 09:00 LT), and then rises very slowly from 10:00 LT with the intensity of the sun to an afternoon maximum between 12:00 and 16:00 LT. It then falls to its minimum just before sunset. Large variations in GPS TEC are observed in daytime, while nighttime variations are found to be minimal at all the stations.

Fig. 2 shows that the magnitude of GPS TEC is generally high during daytime at all locations. The early morning increase in GPS TEC is relatively faster at all stations than the evening decrease in GPS TEC. The daytime GPS TEC values are generally greater than the nighttime values. This can be attributed to the absence of solar radiation at nighttime. It is observed that during the equinoctial days the late afternoon decrease in GPS TEC is equally steep, with occasional post sunset peaks at all the stations. Likewise, during nighttime, the ionosphere maintains an average GPS TEC value of about 15 to $20 \mathrm{TECU}$. During the solstice days, similar features are also seen but with a reduced intensity of 10 to
15 TECU. It can be concluded that TEC increases as the intensity of the sun increases with the time of day. Also, minimum TEC occur around the same time (05:00 LT) on all the days at all the stations, which shows that as the intensity of the sun decreases, TEC decreases. The trend of this result is in accordance with the diurnal variation in TEC at some other locations in the earlier works of Rastogi et al. (1971), Warnant (2000), Rama Rao et al. (2006a, b), Bagiya et al. (2009), Bolaji et al. (2012), and others, which showed that the diurnal variation in TEC shows a short-lived predawn minimum, a steady early morning increase, followed by an afternoon maximum and gradual fall after sunset.

\subsection{Hourly variation in total electron content along latitude}

An interesting feature in the geographic location of Nigeria is the magnetic equator that passes through the northern part of the entire country providing a unique opportunity for studying important ionospheric phenomena, such as TEC variation, the EEJ, the EIA, the equatorial ionization and temperature anomaly (EITA), and the occurrence of intense scintillations.

Figure 3, which displays the hourly variation in TEC as a function of latitude, reveals an occurrence of obvious variation in the hourly plots of TEC along latitudes in all the months in year 2012. Figure 3 was also obtained using surfer software package to generate the local TEC maps for each month. The hourly variation shows a short, steep increase of about 10 to $16 \mathrm{TECU}$ of TEC occurring between 01:00 

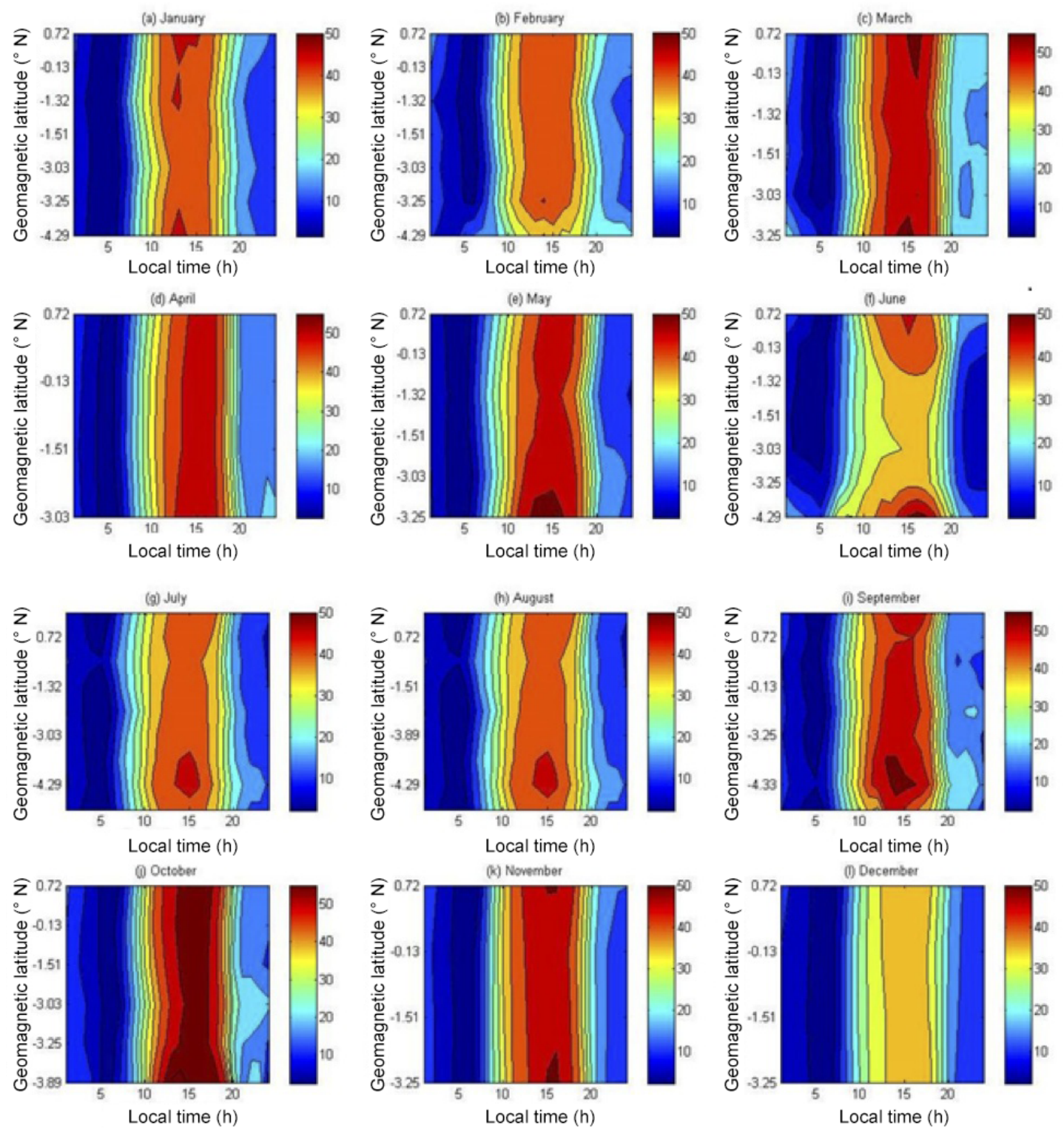

Figure 3. Hourly variation in GPS TEC in all the months along latitude. Data from all stations were used in this figure, except RSUT, CLBR, and FPNO, which were not used to derive maps for the months of March Equinox. Also, RSUT and FPNO were not used to derive maps for the months of December Solstice due to poor data quality.

and 02:00 LT, a sharp and short-lived daytime minimum of about 0 to 2 TECU occurring between 04:00 and 06:00 LT, and a daily maximum of TEC occurring between 12:00 and 14:00 LT. A similar variation was observed for all the months of the year except for the equinox months of March, April, September, and October, which had a sharp and rapid decrease in TEC observed at 20:00 LT with subsequent enhancement at 23:00 LT. After the occurrence of post-sunset enhancement at 23:00 LT, TEC across all the geomagnetic latitudes further gradually and smoothly decayed through midnight until the pre-sunrise hours. The magnitude of TEC post-sunset variation is always greater than its sunrise vari- ation. This post-sunset decrease and enhancement could be attributed to abrupt onset scintillations, plasma bubbles, and the spread-F phenomenon, which was also observed in the work of Bolaji et al. (2012).

However, the spread of GPS TEC at the low-latitude stations in Nigeria is at a minimum during the nighttime and at a maximum during the daytime, which may be attributed to the high ionization due to intense solar radiation. In all the months, a comparatively high value of GPS TEC above 40 TECU was observed between 12:00 and 16:00 LT at all the latitudes except in the month of December when the recorded GPS TEC value was below 40 TECU. This could 

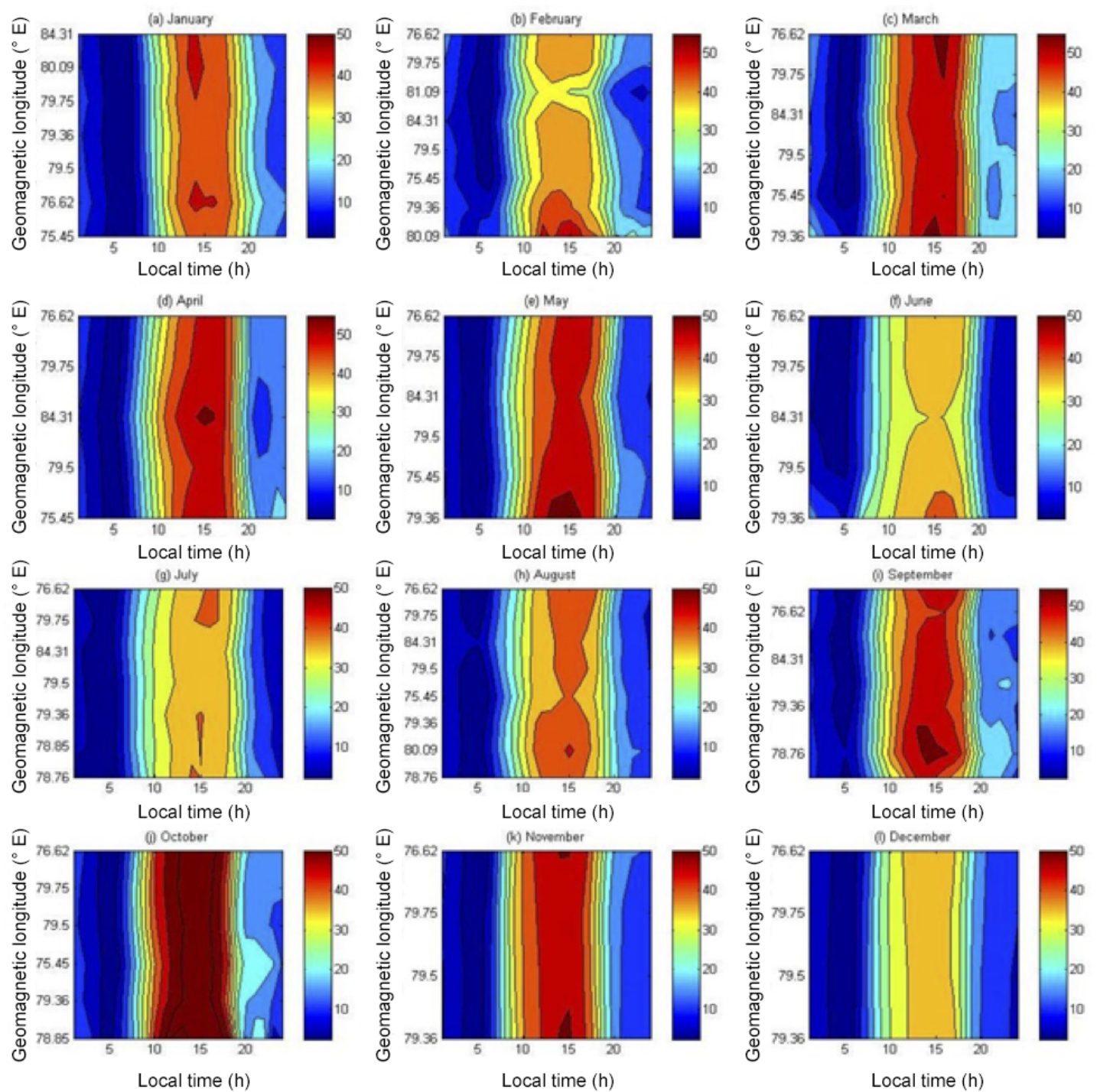

Figure 4. Hourly variation in GPS TEC in all the months along longitude. Data from all stations were used in this figure, except RSUT, CLBR, and FPNO, which were not used to derive maps for the months of March Equinox. Also, RSUT and FPNO were not used to derive maps for the months of December Solstice due to poor data quality.

be due to inhibition of EIA, which is completely inhibited on the day of the counter electrojet, resulting in a lower TEC value. Dabas et al. (1984) and Aravindan and Iyer (1990) reported that the EEJ has a pronounced influence on TEC over a large latitudinal belt from the equator to the $25^{\circ} \mathrm{N}$ dip latitude. Rama Rao et al. (2006a) have shown that the EEJ controls the altitude of lifted plasma and the location of the crest of the equatorial ionization anomaly. It can be concluded that during the daytime the GPS TEC variability at low latitudes is mainly driven by variations in the equatorial electric fields. The equatorial ionization anomaly is a result of the so-called fountain effect, which gives rise to lifting of the equatorial plasma to higher altitudes, during most of the daytime hours. This plasma subsequently diffuses along the geomagnetic field lines to either side of the magnetic equator, owing to the effects of ambipolar diffusion, gravity, and pressure gradients and giving rise to an accumulation of ionization at the F-region altitudes around $\pm 15^{\circ}$ geomagnetic latitudes. This results in the formation of crests of ionization, while simultaneously depleting the ionization over the magnetic equator.

\subsection{Hourly variation in GPS TEC across longitudes}

The hourly variations in GPS TEC across geomagnetic longitudes in all the months of the year 2012 were examined using contour plots as shown in Fig. 4. Figure 4 was obtained using the Surfer software package to generate the local TEC maps for each month. The hourly variation shows an early morn- 
ing steep of about 12 to 14 TECU occurring between 01:00 and 02:00 LT in longitudes $75.45-80.09^{\circ} \mathrm{E}$ and a short-lived predawn minimum of 0-2 TECU occurring between 04:00 and 06:00 LT at all the longitudes. TEC increases with time across all the longitudes until noontime; a postnoon maximum is observed in all the months at about 14:00 LT. TEC decreases gradually as intensity of the solar radiation decreases along all the longitudes. Generally, the hourly variations in TEC along the longitudes show a predawn minimum followed by an early morning steady increase, an afternoon maximum, and then a post-sunset gradual reduction in TEC, with the equinoctial months of March and April depicting nighttime enhancement more prominently at 23:00 LT. The gradual increase in TEC to a maximum value at peak hours of the day at equatorial and low latitudes has been attributed to solar extreme ultraviolet (EUV) ionization coupled with the vertical $\boldsymbol{E} \times \boldsymbol{B}$ drift (Bolaji et al., 2012).

The nighttime decrease is due to the size of the magnetic flux tubes, which are so small that electron content in these tubes collapses rapidly after sunset in response to the low temperatures in the thermosphere at night, leading to low GPS TEC values. During sunrise, the magnetic flux tubes again filled up because of their small volume, resulting in a sudden increase in ionization due to increasing thermospheric temperatures during sunrise (Oron et al., 2013). The observed nighttime GPS TEC enhancement could be attributed to the tidal winds, which blow the ionization across the geomagnetic field. According to Hanson and Mofett (1966), a large-scale electrostatic field is produced at the low latitudes. The electrostatic field is primarily eastward during the day and westward, with the eastward fields being responsible for the upward plasma drift motion and the westward fields during the night, causing the downward drift motion. This plasma fountain reverses during nighttime hours and the northward motion of the crest of ionization during the daytime reverses to a southward motion during the night. The downward motion at the geomagnetic dip equator and the southward motion of ionization could be responsible for the nighttime enhancement of GPS TEC observed in these months.

The GPS TEC depletions, followed by GPS TEC enhancements, as shown in March and April, are associated with small-scale plasma density irregularities. Such irregularities, which result in ionospheric scintillations, can cause transionospheric signal fading, a potential threat to GNSS systems. According to Burke et al. (2004), this behaviour could be attributed to plasma bubbles generated from sunset until sunrise. These plasma irregularities are due to the turbulent ionospheric conditions that give rise to the equatorial spread F (Paznukhov et al., 2012). Factors responsible for these spread-F occurrences have been reported to be either due to the variations in the linear growth rate of the Rayleigh-Taylor instabilities as a result of the electrodynamics of the ionosphere, or to the atmospheric gravity waves. It is furthermore reported that for the African equatorial region,

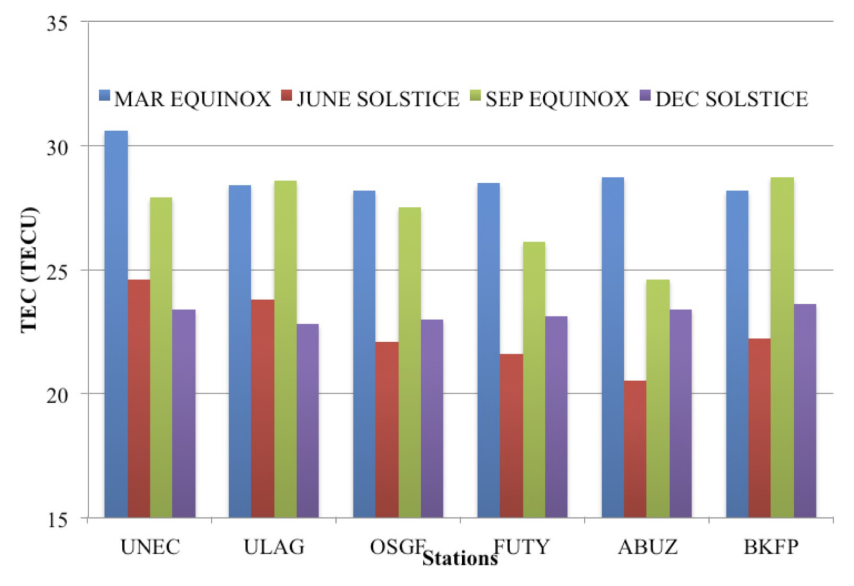

Figure 5. Seasonal TEC variations across some of the study areas in Nigeria.

scintillation occurrence is most frequent when the solar terminator aligns with the geomagnetic field (Paznukhov et al., 2012). The months of June, July, and December exhibit lower values of GPS TEC with a magnitude of less than 50 TECU compared to other months, which have more than 50 TECU across all the longitudes. This implies that the formation of EIA is weaker in those months with less than 50 TECU.

\subsection{Seasonal variation in GPS total electron content}

Seasonal effects were investigated using Lloyd's seasonal classification (Eleman, 1973); the months of the year were classified into three seasons based on the movement of the sun: December Solstice or D season (November, December, January, and February), Equinox or E season (March, April, September, and October), and June Solstice or J season (May, June, July, and August). Since E season shows significant variations in months, we further classified E season into March Equinox (March and April) and September Equinox (September and October) (Bilitza et al., 2004; Rabiu et al., 2007; Oladipo et al., 2009). The seasonal values of GPS TEC, plotted in Fig. 5, were estimated by finding the average of the monthly means of TEC values under a particular season as shown in Table 2 with their respective standard deviation (SD).

Figure 5 presents the seasonal variation in TEC across some of the study areas considered for this study. Generally, the seasonal variation depicts a semi-annual distribution with equinoctial maxima ( 25-30 TECU) around minima in solstices $(\sim 20-25$ TECU). December Solstice magnitude is slightly higher than the June Solstice magnitude at all stations (except at ULAG and UNEC; see Table 2 for a full list of abbreviations), while March Equinox magnitude is also slightly higher than September Equinox magnitude at all stations. This shows a seasonal asymmetry in the ionosphere in the solstices and equinoxes. Thus, the seasonal variation shows a semi-annual pattern, with a maximum in 
Table 2. Seasonal mean values of TEC.

\begin{tabular}{llrrrr}
\hline ID & Location & $\begin{array}{r}\text { March Equinox } \\
\text { Mean } \pm \text { SD }\end{array}$ & $\begin{array}{r}\text { June Solstice } \\
\text { Mean } \pm \text { SD }\end{array}$ & $\begin{array}{r}\text { September Equinox } \\
\text { Mean } \pm \text { SD }\end{array}$ & $\begin{array}{r}\text { December Solstice } \\
\text { Mean } \pm \text { SD }\end{array}$ \\
\hline RSUT & Port Harcourt & - & $21.70 \pm 13.02$ & $24.00 \pm 16.76$ & - \\
CLBR & Calabar & - & $23.00 \pm 14.19$ & $30.96 \pm 18.67$ & $25.82 \pm 15.22$ \\
FPNO & Owerri & - & $22.40 \pm 14.63$ & $30.00 \pm 19.87$ & - \\
UNEC & Enugu & $30.60 \pm 17.02$ & $24.60 \pm 14.71$ & $27.90 \pm 18.63$ & $23.40 \pm 14.93$ \\
ULAG & Lagos & $28.40 \pm 18.07$ & $23.80 \pm 15.30$ & $28.60 \pm 18.36$ & $22.80 \pm 14.51$ \\
OSGF & Abuja & $28.20 \pm 17.38$ & $22.10 \pm 14.52$ & $27.50 \pm 18.64$ & $23.00 \pm 14.74$ \\
FUTY & Yola & $28.50 \pm 18.49$ & $21.60 \pm 13.88$ & $26.10 \pm 17.56$ & $23.10 \pm 15.18$ \\
ABUZ & Zaria & $28.70 \pm 17.71$ & $20.50 \pm 8.48$ & $24.60 \pm 12.87$ & $23.40 \pm 14.88$ \\
BKFP & Kebbi & $28.20 \pm 17.59$ & $22.20 \pm 14.95$ & $28.70 \pm 19.06$ & $23.60 \pm 15.05$ \\
\hline
\end{tabular}

March Equinox, followed by September Equinox, December Solstice, and June Solstice. Earlier on, a similar semi-annual variation was observed in TEC by Bolaji et al. (2013) and Rabiu et al. (2014) while working at stations within Nigeria. The semi-annual variation in Fig. 5 is significant from ABUZ to FUTY, but became insignificant from ULAG; this observation could be due to the EIA initiating redistributions of semi-annual variation as plasma moves along the southern crest.

Wu et al. (2004) and Rama Rao et al. (2006a) independently argued that the seasonal variation pattern in GPS TEC could be explained by the seasonal changes in atmospheric composition. Earlier, Titheridge (1974) reported a worldwide semi-annual variation in atmospheric composition, with the ratio $\mathrm{O} / \mathrm{N}_{2}$ (the relative densities of atomic oxygen and molecular nitrogen) at a maximum near the equinoxes. Also, Rama Rao et al. (2006) argued that the lower values of GPS TEC during the solstice days may be attributed to the low ionization densities due to the reduced production rates indicated by the reduced $\mathrm{O} / \mathrm{N}_{2}$ ratios owing to the increased scale height of $\mathrm{N}_{2}$ as reported by Titheridge (1974). Rishbeth et al. (2000) and the references therein attributed the seasonal variations in the ionosphere to changes in the neutral air composition due to the large-scale thermospheric dynamics, changes in atmospheric turbulence, inputs from atmospheric waves, and variations in geomagnetic activities. Several authors, including Quattara et al. (2009) and Adebesin et al. (2015), have reported distinct seasonal variations, similar to our findings, in the equatorial ionosphere in the western African region using ionosonde measurements.

The semi-annual variation in the GPS TEC could also be due to the combined effect of the solar zenith angle and magnetic field geometry (Wu et al., 2004; Bagiya et al., 2008). Rabiu (2004) observed semi-annual variation with equinoctial maxima in ranges of $H, D$, and $Z$ components of the geomagnetic field and suggested the cause may be due to one or more of three models commonly referred to as axial, equinoctial, and Russell-McPherron mechanisms (for example Clua de Gonzalez, et al., 1993, 2001; Russell and McPherron, 1973; Legrand and Simon, 1989; Simon and
Legrand, 1989; Crooker and Siscoe, 1986; Orlando, et al., 1993; and references therein). Olatunji (1967), Scherliess and Fejer (1999), Bailey et al. (2000), and Liu et al. (2006, 2009) suggested that daytime $\boldsymbol{E} \times \boldsymbol{B}$ drift velocities are larger in the equinoctial months (February, March, April, August, September, and October) and winter months (November, December, and January) than in the summer months (May, June, and July) and this could result in semi-annual variation. Olatunji (1967), Bailey et al. (2000), and Liu et al. (2006, 2009) related this semi-annual variation to the variation in the noon solar zenith angle, which is an important factor for the production of ionization. Wu et al. (2004), Rama Rao et al. (2006b), and Lee et al. (2010) attributed the semi-annual variation to a combined effect of solar zenith angle and geomagnetic field geometry.

\section{Conclusions}

This study presents the diurnal and seasonal variation in GPS-measured TEC over Nigeria using simultaneous measurements made with the GPS network receivers, covering geomagnetic coordinates bounded between longitudes 75.45 and $84.31^{\circ} \mathrm{E}$ and latitudes -4.33 and $0.72^{\circ}$. The diurnal and seasonal variations in GPS TEC derived from all the stations were studied for a 12-month period from 1 January to 31 December 2012. Our observations revealed that the diurnal variation at all stations reached its maximum value between 12:00 and 14:00 LT. Similarly, the daily minimum in GPS TEC occurs between 05:00 and 06:00 at all the stations. The diurnal variation in GPS TEC shows a range of about 0 to $60 \mathrm{TECU}$ at all the stations. It shows that the GPS TEC reaches a maximum during the equinox months and is lowest during the solstice months. The lower value of GPS TEC during these months is attributed to the low ionization densities, which are due to the reduced production rates (indicated by $\mathrm{O} / \mathrm{N}_{2}$ ratio), owing to the increased scale height of $\mathrm{N}_{2}$ (Titheridge, 1974).

The monthly distribution of latitudinal and longitudinal variations in TEC with respect to time varies from a predawn 
minimum to an afternoon maximum and then decreases to attain minimum. The latitudinal and longitudinal variations show a short, steep increase of about 12 to 16 TECU occurring between 01:00 and 02:00 LT and a sharp and short-lived daytime minimum of about 0 to 2 TECU occurring between 04:00 and 06:00 LT. TEC increases with time across all the longitudes until noontime; postnoon maximum is observed in all the months at about 14:00 LT. TEC decreases gradually and reaches minimum at about sunset as intensity of the solar radiation decreases along all the longitudes. The seasonal variations show that TEC reaches a maximum during the equinox months and is lowest during the solstice months, thus revealing an asymmetric semi-annual pattern.

Data availability. The raw GPS (observable) data in RINEX format for the nine stations engaged in this research were obtained from the GNSS continuously operating reference stations (CORSs) of the Nigerian GNSS Reference Network (NIGNET) operated by the Office of the Surveyor General of the Federation (OSGoF) of Nigeria. The NIGNET data are freely available to the public at www.nignet.net.

Competing interests. The authors declare that they have no conflict of interest.

Acknowledgements. The GPS RINEX data used for this research were obtained from the public archives of the Office of the Surveyor General of the Federal Government of Nigeria, which is the mapping agency of Nigeria responsible for operation and maintenance of the Nigerian GNSS reference network NIGNET CORS. We are also grateful to Gopi Krishna Seemala and the Institute for Scientific Research, Boston College, Boston, MA, USA, for making the GPS TEC analysis software available. The authors remain grateful to the three anonymous reviewers for the positive impact they made on this work.

The topical editor, C. Jacobi, thanks the three anonymous referees for help in evaluating this paper.

\section{References}

Adebesin, B. O., Rabiu, A. B., Adeniyi, J. O., and AmoryMazaudier, C.: Nighttime morphology of vertical plasma drifts at Ouagadougou during different seasons and phases of sunspot cycles 20-22, J. Geophys. Res.-Space Physics, 120, 10020-10038, https://doi.org/10.1002/2015JA021737, 2015.

Akala, A. O., Oyeyemi, E. O., Somoye, E. O., Adeloye, A. B., and Adewale, A. O.: Variability of $f o \mathrm{~F}_{2}$ in the African equatorial ionosphere, Adv. Space Res., 45, 1311-1314, 2010.

Akala, A. O., Doherty, P. H., Valladares, C. E., Carrano, C., and Sheehan, R.: Statistics of GPS scintillations over South America at three levels of solar activity, Radio Sci., 46, RS5018, https://doi.org/10.1029/2011RS004678, 2011.

Akala, A. O., Doherty, P. H., Carrano, C. S., Valladares, C. E., and Groves, K. M.: Impacts of ionospheric scintillations on GPS re- ceivers intended for equatorial aviation applications, Radio Sci., 47, RS4007, https://doi.org/10.1029/2012RS004995, 2012.

Akala, A. O., Rabiu, A. B., Somoye, E. O., Oyeyemi, E. O., and Adeloye, A. B.: The Response of African equatorial GPS-TEC to intense geomagnetic storms during the ascending phase of solar cycle 24, J. Atmos. Sol.-Terr. Phy., 98, 50-62, 2013.

Appleton, E. V.: Two anomalies in the ionosphere, Nature, 157, 691-693, 1946.

Aravindan, P. and Iyer, K. N.: Day-to-day variability in ionospheric electron content at low latitudes, Planet Space Sci., 38, 743-750, 1990

Ayorinde, T. T., Rabiu, A. B., and Amory-Mazaudier C.: Interhourly variability of Total Electron Content during the quiet condition over Nigeria within the Equatorial Ionization Anomaly region, J. Atmos. Sol.-Terr. Phy., 145, 21-33, 2016.

Bagiya, M. S., Joshi, H. P., Iyer, K. N., Aggarwal, M., Ravindran, S., and Pathan, B. M.: TEC variations during low solar activity period (2005-2007) near the Equatorial Ionospheric Anomaly Crest region in India, Ann. Geophys., 27, 1047-1057, https://doi.org/10.5194/angeo-27-1047-2009, 2009.

Bailey, G. J., Su, Y. Z., and Oyama, K.-I.: Yearly variations in the low-latitude topside ionosphere, Ann. Geophys., 18, 789-798, https://doi.org/10.1007/s00585-000-0789-0, 2000.

Bilitza, D.: International reference ionosphere, Radio Sci., 36, 261275, 2001.

Bolaji, O. S., Adeniyi, J. O., Radicella, S. M., and Doherty, P. H.: Variability of total electron content over an equatorial West African station during low solar activity, Radio Sci., 47, RS1001, https://doi.org/10.1029/2011RS004812, 2012.

Bolaji, O. S., Adeniyi, J. O., Adimula I. A., Radicella S. M., and Doherty, P. H.: Total electron content and magnetic field intensity over Ilorin, Nigeria, J. Atmos. Sol.-Terr. Phy., 98, 1-11, 2013.

Burke, W. J., Huang, C. Y., Gentile, L. C., and Bauer, L.: Seasonallongitudinal variability of equatorial plasma bubbles, Ann. Geophys., 22, 3089-3098, https://doi.org/10.5194/angeo-22-30892004, 2004.

Chauhan, V., Singh, O. P., and Singh, B.: Diurnal and seasonal variation of GPS TEC during a low solar period as observed at a low latitude station Agra, Indian J. Radio Space, 40, 26-36, 2011.

Clua de Gonzalez, A. L., Gonzalez, W. D., and Dutra, S. L. G.: Periodic variation in the geomagnetic activity: A study based on the Ap index, J. Geophys. Res., 98, 9215-9231, 1993.

Clua de Gonzalez, A. L., Silbergleit, V. M., Gonzalez, W. D., and Tsurutani, B. T.: Annual variation of geomagnetic activity, J. Atmos. Sol.-Terr. Phy., 63, 367-374, 2001.

Crooker, N. U. and Siscoe, G. L.: The effect of solar wind on the terrestrial environment, in: Physics of the Sun, Vol. III, Astrophysics and Solar-Terrestrial Relations, edited by: Sturrock, P. A., Holzer, T. E., Mihalas, D. A., Ulrich, R. K., Geophysics Astrophysics Monographs, D. Reidel, Hinghem, MA, 193-249, 1986.

Dabas, R. S., Bhuyan, P. K., Tyagi, T. R., Bharadwaj, R. K., and Lal, J. B.: Day to day changes in ionospheric electron content at low latitudes, Radio Sci., 19, 746-749, 1984.

Eleman, F.: The geomagnetic field, in: Cosmical Geophysics, Chap. 3, edited by: Egeland, A., Holter, O., and Omholt, A., Scandinavian University Books, Oslo, 45-62, 1973.

Hanson, W. B. and Moffett, R. J.: Ionization transport effects in the equatorial region, J. Geophys. Res., 71, 5559-5572, 1966. 
Langley, R., Fedrizzi, M., Paula, E., Santos, M., and Komjathy, A.: Mapping the low latitude ionosphere with GPS, GPS World, 13, 41-46, 2002.

Lee, C. C., Chuo, Y. J., and Chu, F. D.: Climatology of total electron content near the dip equator under geomagnetic quiet-conditions, J. Atmos. Sol.-Terr. Phy., 72, 207-212, 2010.

Legrand, J. P and Simon, P. A.: Solar Cycle and geomagnetic activity: A review for Geophysicists. Part I: The contributions to geomagnetic activity of shock waves and of the solar wind, Ann. Geophys., 7, 565-578, 1989.

Liu, L. and Chen, Y.: Statistical analysis of solar activity variations of total electron content derived at Jet Propulsion Laboratory from GPS observation, J. Geophys. Res., 114, A10311, https://doi.org/10.1029/2009JA014533, 2009.

Liu, L., Wan, W., Ning, B., Pirog, I. M., and Kurkin, V. I.: Solar activity variations of the ionospheric peak electron density, J. Geophys. Res., 110, A08304, https://doi.org/10.1029/2006JA011598, 2006.

Mannucci, A. J., Wilson, B. D., and Edwards, C. D.: A new method for monitoring the Earth's ionospheric total electron content using the GPS global network, Institute of Navigation, 1323-1332, 22-24 September 1993, Salt Lake City, Utah, 1993.

Mukherjee, S., Sarkar, S., Purohit, P. K., and Gwal, A. K.: Seasonal Variation of Total Electron Content at crest of equatorial anomaly station during low solar activity conditions, Adv. Space Res., 46, 291-295, 2010.

Natali, M. P. and Meza, A.: Annual and semiannual variations of vertical total electron content during high solar activity based on GPS observations, Ann. Geophys., 29, 865-873, https://doi.org/10.5194/angeo-29-865-2011, 2011.

Oladipo, O. A., Adeniyi, J. O., Radicella, S. M., and Obrou, O. K.: Variability of equatorial ionospheric electron density at fixed heights below the f2 peak, J. Atmos. Terr. Phys., 70, 1056-1065, 2009.

Olatunji, E. O.: The total columnar electron content of the equatorial ionosphere, J. Atmos. Terr. Phys., 29, 277-285, 1967.

Olwendo, O. J., Baki, P., Cilliers, P. J., Mito, C, and Doherty, P.: Comparison of GPS TEC variations with IRI-2007 TEC prediction at equatorial latitudes during a low solar (2009-2011) phase over the Kenyan region, Adv. Space Res., 52, 1770-1779, 2013.

Orlando, M., Moreno, G., Parisi, M., and Storini, M.: Semiannual variation of geomagnetic activity and solar wind parameters, Geophys. Res. Lett., 20, 2271-2274, 1993.

Oron, S., Ujanga, F. M. D., and Ssenyonga, T. J.: Ionospheric TEC Variations during the ascending solar activity phase at an equatorial station, Uganda, Indian J. Radio Space, 42, 7-17, 2013.

Ouattara, F., Amory-Mazaudier, C., Fleury, R., Lassudrie Duchesne, P., Vila, P., and Petitdidier, M.: West African equatorial ionospheric parameters climatology based on Ouagadougou ionosonde station data from June 1966 to February 1998, Ann. Geophys., 27, 2503-2514, https://doi.org/10.5194/angeo27-2503-2009, 2009.

Pandey, V. K., Sethi, N. K., and Mahajan, K. K.: Equivalent slab thickness and its variability: a study with incoherent scatter measurements, Adv. Space Res., 27, 61-64, 2001.

Paznukhov, V. V., Carrano, C. S., Doherty, P. H., Groves, K. M., Caton, R. G., Valladares, C. E., Seemala, G. K., Bridgwood, C. T., Adeniyi, J., Amaeshi, L. L. N., Damtie, B., D’Ujanga Mutonyi, F., Ndeda, J. O. H., Baki, P., Obrou, O. K., Okere, B., and Tsidu, G. M.: Equatorial plasma bubbles and L-band scintillations in Africa during solar minimum, Ann. Geophys., 30, 675-682, https://doi.org/10.5194/angeo-30-675-2012, 2012.

Rabiu, A. B.: The ranges of subauroral geomagnetic field elements, Nig. J. Pure and Applied Phys., 3, 51-62, 2004.

Rabiu, A. B., Mamukuyomi, A. I., and Joshua, E. O.: Variability of equatorial ionosphere inferred from geomagnetic field measurements, B. Astron. Soc. India, 37, 607-618, 2007.

Rabiu, A. B., Onwumechili, C. A., Nagarajan, N., and Yumoto, K.: Characteristics of equatorial electrojet over India determined from a thick current shell model. J. Atmos. Sol.-Terr. Phy., 92, 105-115, 2013.

Rabiu, A. B., Adewale, A. O., Abdulrahim, R. B., and Oyeyemi, E. O.: TEC derived from some GPS stations in Nigeria and comparison with the IRI and Ne quick models, Adv. Space Res., 53, 1290-1303, https://doi.org/10.1016/j.asr.2014.02.009, 2014.

Rama Rao, P. V. S., Gopi Krishna, S., Niranjan, K., and Prasad, D. S. V. V. D.: Temporal and spatial variations in TEC using simultaneous measurements from the Indian GPS network of receivers during the low solar activity period of 2004-2005, Ann. Geophys., 24, 3279-3292, https://doi.org/10.5194/angeo24-3279-2006, 2006a.

Rama Rao, P. V. S., Gopi Krishna, S., Niranjan, K., and Prasad, D. S. V. V. D.: Study of spatial and temporal characteristics of Lband scintillations over the Indian low-latitude region and their possible effects on GPS navigation, Ann. Geophys., 24, 15671580, https://doi.org/10.5194/angeo-24-1567-2006, 2006 b.

Rama Rao, P. V. S., Srirama Rao, M., and Satyam, M.: Diurnal and seasonal trends in TEC values observed at Waltair, Indian J. Radio Space, 6, 233-235, 1997.

Rastogi, R. G. and Rajaram, G.: Electrojet effects on the equatorial F-region during magnetically quiet and disturbed days, Indian Journal of Pure and Applied Physics, 9, 531-536, 1971.

Rishbeth, H., Müller-Wodarg, I. C. F., Zou, L., Fuller-Rowell, T. J., Millward, G. H., Moffett, R. J., Idenden, D. W., and Aylward, A. D.: Annual and semiannual variations in the ionospheric F2-layer: II. Physical discussion, Ann. Geophys., 18, 945-956, https://doi.org/10.1007/s00585-000-0945-6, 2000.

Russell, C. T. and McPherron, R. L.: Semi-annual variation of geomagnetic activity, J. Geophys. Res., 78, 92-108, 1973.

Scherliess, L. and Fejer, B. G.: Radar and satellite global equatorial F-region vertical drift model, J. Geophys. Res., 104, 6829-6842, 1999.

Simon, P. A. and Legrand, J.-P.: Solar Cycle and geomagnetic activity: A review for Geophysicists. Part II: The solar sources of geomagnetic activity and their links with sunspot cycle activity, Ann. Geophys., 7, 579-594, 1989.

Titheridge, J. E.: Changes in atmospheric composition inferred from ionospheric production rates, J. Atmos. Terr. Phys., 36, 12491257, 1974.

Warnant, R.: The increase of ionospheric activity as measured by GPS, Earth Planets Space, 52, 1055-1060, 2000.

Wu, C. C., Fryb, C. D., Liu, J. Y., Lioud, K., and Tseng, C. L.: Annual TEC variation in the equatorial anomaly region during the solar minimum: September 1996-August 1997, J. Atmos. Sol.Terr. Phys., 66, 199-207, 2004.

Yeh, K. C., Franke, S. J., Andreeva, E. S., and Kunitsyn, V. E.: An investigation of motions of the equatorial anomaly crest, Geophys. Res. Lett., 28, 4517-4520, 2001. 